\title{
Scientific Uncertainty and Biodiversity Inventory
}

\author{
Indra Prasad Subedi ${ }^{*}$
}

\author{
${ }^{I}$ Central Department of Zoology, Tribhuvan University, Kirtipur, Kathmandu, Nepal
}

\section{*CORRESPONDENCE: \\ Indra Prasad Subedi \\ Central Department of Zoology, \\ Tribhuvan University, Kirtipur, \\ Kathmandu, Nepal \\ Email: ipsubedi@cdztu.edu.np}

\section{ISSN : 2382-5359(Online), 1994-1412(Print)}

DOI:

https://doi.org/10.3126/njst.v20i1.39435

\section{ACCESS THE ARTICLE ONLINE}

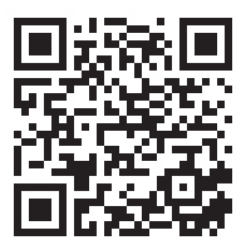

\section{CONFILICT OF INTEREST: None}

Copyright: The Author(s) 2020. This is an open access article under the $\underline{\mathbf{C C} \text { BY license. }}$

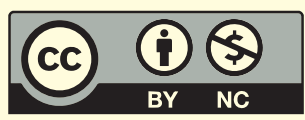

\begin{abstract}
All sciences, including biological science, have uncertainty, and they complicate theoretical questions. Uncertainty essentially is a mark of good science, and its efficacious communication is even essential for better decisions. Explaining the research work uncertainties indicates that the scientists are aware of the vital difference between the known and the unknown. Uncertainty is equally significant in biodiversity studies. Species composition of any area can't be predicted with certainty because of interwoven relationships between species diversity and climatic and anthropogenic factors. Good survey planning with acceptable animal welfare practices could lead to asymptote for inventory of any particular area. Scientists can handle uncertainty in their studies by sensible statistics and reasonably large sample size.
\end{abstract}

Keywords: Biology; communication, diversity; organism; species

\section{INTRODUCTION}

A few months ago, my lipid profile values were found slightly beyond the normal range. My regular doctor prescribed me medicines to maintain a standard range of low-density lipoproteins (LDL) based on the medical report. However, when this report was shown to other doctors for multiple opinions, for safety's sake, some were in favour of me not taking medicines at all! These medical experts had handled numerous high LDL cases, and there are enumerable research findings that suggest different yet appropriate decisions. Despite the availability of much literature with standard statistical analyses on the same issue, we can't say which one of the experts' decisions

is correct as it may just be an opinion. The crux of controversial recommendations is associated with the nature of biological sciences, the so-called lower sciences, where decision-making involves uncertainty. Here Mendel's stochastic model works, only predictions for future states can be made, but nothing can be said about them with certainty.

Consequently, studies related to biodiversity inventory need to work with organisms and their identity up to the species level. The species' problem is one of the most prominent problems in biology. There is no standard view on species' origin, biological meaning, and species taxa's delimitation (Mayr 2004). None of the species' concepts is perfect; all are riddled with certain limitations. New species are produced as a result of a complex evolutionary process ranging from gradual changes to random mutations. A considerably high degree of divergence and uncertainty exists about almost every aspect of species (Mayr 2004) which might have arisen from different sources. Hey et al. (2013) mentioned two sources of species uncertainty; one that is a semantic confusion, and a second that is caused by the inherent uncertainty of evolutionary entities. The former can be dispelled with careful communication, whereas the latter is a conventional scientific uncertainty that can only be mitigated by research. This scientific uncertainty cannot be 'solved' or stamped out, but neither needs it to be ignored or feared." 
Uncertainty helps scientists to take full advantage of scientific research, and thereby convey the salient points of uncertainty in scientific communication. Both too much and too little confidence in science's truth, its unquestionability, can be harmful since one can face unexpected problems in the first case or can miss opportunities in the later (Fischhoff \& Davis 2014). This paper discusses the importance of uncertainty in scientific research and especially in biodiversity inventory studies. It further suggests the ways of handling uncertainty, focusing on the wise application of statistics.

Uncertainty essentially is a mark of good science. When scientists explain the uncertainties in their research work, it does not mean that they cannot make decisions, but that they are aware of the vital difference between the known and the unknown. Perhaps, anybody discouraged by the existence of uncertainty would mean he or she is missing out on meaningful discussions about the likely development of new knowledge. One of the critical uncertainties concerning facts is: What happens if we make any particular choice? Fjelland (2002) pointed out two consequences of recognizing uncertainty for science and science policy, one concerning the uses of statistics (more generally, the burden of proof) and another concerning models' use. The paper is based upon the available resources to provide perspectives on the crucial issue of uncertainty in scientific research.

\section{BIODIVERSITY INVENTORY AND UNCERTAINTY}

Organismal diversity cannot be studied as a whole, and to understand it we must segregate it into a hierarchy from higher to lower taxa (kingdom, phylum, class, order, family, genus \& species). The basic unit of taxonomy is species. Reductionism considers that a complete explanation can be done only at the lowest level of organization. It is not always necessary or possible in biology; instead, analysis is always a critical methodology to study complex systems (Mayr 2004).

The whole is more than the sum of its parts. Take the human body or other animals' bodies as examples. Keeping all the physical and chemical components of a body together in the same proportion as that of a living body cannot produce life. A holistic approach studies the interactions of higher levels in a complex system which conflicts with various attempts of philosophers, physicalists, and some biologists to reduce biology to physics or chemistry (Mayr 2004). It is not always fair and complete to apply all the basic principles of philosophy coined based on physics or chemistry in explaining all biological phenomena since biology is an autonomous science. Biology has several unique characteristics not found in other sciences. For instance, several animals, including some ant species, exhibit phenotypic plasticity, i.e., one genotype's ability to produce more than one phenotype when exposed to different environments also bears testimony against reductionism. Popper (1974) concluded, "as a philosophy, reductionism is a failure... we live in a universe of emergent novelty; of a novelty which, as a rule, is not completely reducible to any of the preceding stages."

Two long-standing hypotheses concerning organismal distribution patterns include the altitudinal gradient hypothesis and habitat favorability hypothesis. As per the altitudinal gradient hypothesis, we can predict a decrease in species richness with increasing altitude. On the other hand, the "habitat favorability hypothesis" indicates that there are more notable species in mesic habitats (habitats near water resources) compared to xeric habitats (habitats far from water resources) independent of altitude. Several studies corroborate these hypotheses (such as Araujo and Fernandes 2003; Bernadou et al. 2013; Marathe et al. 2020). The distribution patterns of organisms may vary in specific regions or conditions, and it is not sure that the distribution patterns of organisms always follow these hypotheses. Several research findings focused on mid-elevation peaks (Botes et al. 2006; Bharti et al. 2013; Longino \& Branstetter 2019).

Further, various climatic parameters (temperature, precipitation, relative humidity) or anthropogenic causes are responsible for defining species diversity patterns in any area (Araujo \& Fernandes 2003; Malsch et al. 2008; Bernadou et al. 2013; Subedi \& Budha 2020). Because of these interwoven relationships determining species diversity and composition, it is tough to predict species composition in any area with certainty. In this context, I agree to some extent, with Popper's basic idea of falsification. It is valid only in the sense that more instances do not increase certainty. But a single report of the occurrence of any unknown species in any area confirms the existence of that particular species. Thus, falsification is neither wrong nor a complete idea.

The collection of specimens could be essential in many biodiversity inventories, particularly for smaller invertebrates whose identification up to species level in the field is not possible. In such cases, good survey planning and applying the appropriate methodology should address ethical problems associated with acceptable animal welfare practices. As per the National Committee for research Ethics in Science and Technology (NENT 2016) 
guidelines, the researchers should clarify the degree of uncertainty in their research, evaluate the risk associated with the research findings, and strive to observe the precautionary principle. Further, they should proceed with due care and respect animal welfare when preparing and conducting experiments.

\section{HANDLING UNCERTAINTY}

Researchers need to handle uncertainty in their studies by the wise application of statistics and also by taking reasonably large samples. Good statistical practice highlights sound study design principles, contextual interpretation of results, complete reporting, and appropriate logical and quantitative understanding of data summaries' meaning (Wasserstein 2016). "The ASA statement on p-values and statistical significance would shed light on an aspect of our field that is too often misunderstood and misused in the broader research community, and, in the process, provides the community a service" (Wasserstein \& Lazar 2016). However, the single index should not substitute for scientific reasoning (Wasserstein 2016). The p-values are not as reliable as many scientists assume (Nuzzo 2014). We usually look for the instances where the hypothesis proved right while testing a hypothesis, but this does not always work. In the Black Swan, Taleb (2007) writes "we can get closer to the truth by negative instances, not by verification! It is misleading to build a general rule from observed facts. Contrary to conventional wisdom, our body of knowledge does not increase from a series of confirmatory observations."

\section{CONCLUSION}

Uncertainty is natural to all sciences. Effective communication of uncertainty is a big challenge to get rid of confusions. Fischhoff and Davis (2014) offer protocol for summarizing many possible sources of uncertainty with the goals of better decisions, better science, and better support for science. The scientific uncertainty cannot be solved or stopped, but neither needs it to be ignored or scared. However, scientists can handle uncertainty by the practical application of statistics and also by taking reasonably large samples.

\section{ACKNOWLEDGEMENT}

The author is grateful to Prof Ragnar Fjelland, the University of Bergen, and anonymous reviewers for their insightful comments on the manuscript.

\section{REFERENCES}

1. Araujo, L.M. and G.W. Fernandes. 2003. Altitudinal patterns in a tropical ant assemblage and variation in species richness between habitats. Lundiana 4(2): 103109.

2. Bernadou, A., R. Cereghino, H. Barcet, M. Combe, X. Espadler, and V. Fourcassie. 2013. Physical and land-cover variables influence ant functional groups and species diversity along elevational gradients. Landscape Ecology 28(7):1387-1400.

3. Bharti, H., Y.P. Sharma, M. Bharti, and M. Pfeiffer. 2013. Ant species richness, endemicity and functional groups, along an elevational gradient in the Himalayas. Asian Myrmecology 5:79-101.

4. Botes, A., M.A. McGeoch, H.G. Robertson, A.V. Niekerk, H.P. Davids, and S. L. Chown. 2006. Ants, altitude and change in the northern Cape Floristic Region. Journal of Biogeography 33:71-90.

5. Fischhoff, B. and A.L. Davis. 2014. Communicating scientific uncertainty, PNAS 111:13664-13671.

6. Fjelland, R. 2002. Facing the problem of uncertainty, Journal of Agricultural and Environmental Ethics 15:155-169.

7. Hey, J., R.S. Walpes, M.L. Arnold, K.R. Butlin and R.G. Harrison. 2003. Understanding and confronting species uncertainty in biology and conservation. Trends in Ecology \& Evolution 18(11):597-603.

8. Longino, J. T. and M.G. Branstetter. 2019. The truncated bell: an enigmatic but pervasive elevational diversity pattern in Middle American ants. Ecography 42:272-283. doi: 10.1111/ecog.03871

9. Malsch, A.K.F., B. Fiala, U. Maschwitz, M. Mohamed, J. Nais and E. Linsenmair. 2008. An analysis of declining ant species richness with increasing elevation at Mount Kinabalu, Sabah, Borneo. Asian Myrmecology 2:33-49.

10. Marathe, A., D.R. Priyadarsanan, J. Krishnaswamy and K. Shanker. 2020. Spatial and climatic variables independently drive elevational gradients in ant species richness in the Eastern Himalaya. PLoS ONE 15(1): e0227628. https://doi. org/10.1371/journal. pone. 0227628

11. Mayr, E. 2004. What makes biology unique? Considerations on the autonomy of scientific discipline. Cambridge University Press. 247p.

12. NENT, 2016. Guidelines for research ethics in science and technology, The National Committee for Research 
Ethics in Science and Technology, Norway, 20p.

13. Nuzzo, R.L. 2014. Scientific method: Statistical errors, Nature 506:150-152.

14. Popper, K. 1974. Unended quest, an intellectual autobiography. La Salle, IL, Open Court Publishing.

15. Subedi, I. P. and P. B. Budha. 2020. Diversity and distribution patterns of ants along elevational gradients. Nepalese Journal of Zoology 4(1):44-49.
16. Taleb, N.N. 2007. The Black Swan, The impact of the highly improbable. Random House, USA, 366p.

17. Wasserstein, R.L. 2016. ASA statement on statistical significance and P-values. The American Statistician 70(2):129-133

18. Wasserstein, R.L. and N.A. Lazar. 2016. The ASA's Statement on p-Values: Context, process, and purpose, The American Statistician 70(2):129-133. 